\title{
Quando uma resenha encontra o si-mesmo do resenhador, apontamentos muito pessoais sobre um catálogo
}

\author{
Flávio Leonel Abreu da Silveira ${ }^{1}$
}

Peço desculpas ao leitor se a resenha que ora apresento sobre o catálogo da exposição fotográfica, intitulado Cartas aos Narradores Urbanos. Etnografia de rua na Porto Alegre das Intervenções Artísticas, por vezes,tende a revelar um tom pessoal, quiçá afetivo, sobre o material resenhado. É que somente depois que me propus a realizá-lo foi que compreendi o quanto estou implicado, processualmente, nele. Não tenho relação direta com oinstigante esforço coletivo de produção ético-estética que é o catálogo da exposição que resenho, mas ao manuseá-lo reconheço camadas de memórias que nele se assentam como um devir que me implica. Uma "razão sensível » me liga as suas vibrações, e me vejo na pulsação (inter/transgeracional) desse tempo da duração feliz - para aderir a uma imagem bachelardiana - que é a experiência do Navisual-Biev².

Então, estes escritos antes de configurarem uma resenha no sentido clássico do termo, revelam-se um pequeno experimento narrativo que,por certo, deve torná-lo muito mais um comentário acerca de uma proposta que dura no tempo do que a resenha acerca de um produto acabado, já que na verdade indica um trabalho em processo. Entendo que o conhecimento nunca é senão o esforço cognitivo-afetual do sujeito se pensar em relação aos outros no mundo - e, por isso mesmo, de implicar o si-mesmo na construção de um objeto sensível de pesquisa - que não separa o vivido daquilo que o ultrapassa. Digo isso porque as camadas que percebo no catálogo são muitas, e nelas a minha experiência no mundo também vibra. A partir daí me fixarei em três níveis estratigráficos das memórias que o catálogo reverbera:

1. As camadas de tradições e linhagens. Veja bem, quando estou me referindo às camadas memoriais, não estou dizendo que elas arqueologicamente se sobrepõem umas sobre as

1 Universidade Federal do Pará (UFPA), Brasil.

2 Vejo um continuum entre o Núcleo de Antropologia Visual (NAVISUAL) e o projeto paralelo, mas conexo, do Banco de Imagens e Efeitos Visuais (BIEV) que Cornelia Eckert e Ana Luíza Carvalho da Rocha conduzem em parceria há algumas décadas junto ao Programa de Pós-Graduação em Antropologia Social (PPGAS), da Universidade Federal do Rio Grande do Sul UFRGS).

Iluminuras, Porto Alegre, v. 19, n. 47, p. 291-299, dec, 2018. 
outras como uma espécie de bloco estável. Uma etnografia da duração aplicada ao pensamento antropológico jamais compreenderia as vibrações da vida social acadêmica desta maneira. As camadas aqui se aproximam podendo produzir interposições, tensionamentos e acoplamentos nas suas movimentações e agitações, jogando com as possibilidades de uma matriz disciplinar, incorporando autores mais ou menos distantes a ela, na medida em que,junto a isso, se apropria transcriativamente de linhagens da antropologia urbana brasileira. É por isso que a forma epistolar utilizada pelo coletivo envolvido na pesquisa agencia uma poética sensível de interlocução com (e entre) os autores referidos.

O catálogo como um experimento em antropologia recupera a crítica pós-moderna vinculada ao lugar do antropólogo na feitura do texto, desloca seu lugar não apenas de poder mas de sujeito em campo que necessariamente se vêafetado pelas dinâmicas do mundo urbano que pesquisa em sua cidade - questão longamente debatida por Gilberto Velho em seu diálogo com Roberto DaMatta, bem antes dos pós-modernos. Daí que o tom epistolar, de cartas que entrelaçam observações de campo às reflexões teóricometodológicas propostas pelos autores, com perspectivas por vezes muito próximas, de caráter dialógico, torna a leitura agradável. Há, no meu ponto de vista, algo de sensível e jovial no texto, que aponta para as formas pelas quais esta geração de jovens antropólogos (acompanhada de seus mestres) se apropria dos autores debatidos nas oficinas preparatórias para o exercício de campo; opera com conceitos e produz o texto ao mesmo tempo em que contribui para revigoraro caráter literário da etnografia no contemporâneo.

São cartas sensíveis [e sentimentais, porque não] aos apelos ético-estéticos dos autores que tiveram seus trabalhos lidos pelo grupo, e as abordagens teórico-metodológicas incorporadas nos exercícios praticados. São figuras-guias, são autores que emprestam vigor aos ímpetos etnográficos de uma geração que se aventura na cidade, que deseja conhecer as dinâmicas das e nas metrópoles brasileiras a partir de suas vivências em Porto Alegre, portanto, que se permitem fazer comparações. Há muitas pistas interessantes nos textos dedicados aos autores sobre isto. 
Os autores, nacionais e estrangeiros, são homenageados de uma maneira singela e rica de imagens. Entre cada um deles há um conjunto de narrativas visuais que demonstra a força operatória de seus conceitos transfigurados em imagens acerca da cidade de Porto Alegre. Entre todos eles, e não poderia ser diferente, existe uma poética, um caráter sensível, que os «une em separado» no espaço (as cidades distintas que praticaram/estudaram) e no tempo (as diversas gerações e, por assim dizer, os « espíritos de época » que suscitam). Atentos ao tema da biografia informam brevemente detalhes de suas vidas, das experiências pessoais e acadêmicas de cada autor, como é o caso de Walter Benjamin, Michel De Certeau,William Foote Whyte, Colette Pétonnet,Helio R. S. Silva, José G. C. Magnani, Ana Luiza Carvalho da Rocha e Cornelia Eckert, Ricardo Campos, que têm seus estudos evocados nos exercícios etnográficos praticados pelos jovens antropólogos. Destes me dedicarei a três, por questões pessoais e acadêmicas:

1.1. Helio Silva, meu querido professor e amigo é um mestre na narrativa etnográfica sobre o mundo urbano, seu livro Travesti - a invenção do feminino, a qual resenhei ${ }^{3}$ é uma obra impecável e de enorme potência imagético-textual para aqueles que buscam pensar a heterogeneidade cultural presente nas metrópoles brasileiras. Um livro como este, passados todos esses anos de sua publicação, mobiliza forças capazes de continuar influenciando gerações. Se ele influenciou a minha - ou, mais diretamente a mim - segue influenciando as mais novas. A ética da interação com a alteridade no mundo urbano e as implicações do lugar do antropólogo nesse jogo; a obliquidade do olhar, o sensível nos detalhes, as sutilezas nas formas que emanam na vida social e que o antropólogo atento recolhe como uma ressonância no seu devir, efêmero e fugaz, me parecem as marcas vivas de sua presença na antropologia urbana que realizamos.

1.2. Cornelia Eckert e Ana Luíza Carvalho da Rocha, minhas orientadoras e amigas, a quem também tive a honra de resenhar um livro ${ }^{4}$ conjugam duas dimensões potentes no ato de etnografar o mundo urbano: o olhar atento pousado nas camadas de memórias que se

3 Rev. Bras. Ciências Sociais, v.10 n. 27 São Paulo, 1995.

4 Horizontes Antropológicos, vol.12 n. 26 Porto Alegre, 2006. 
assentam nos lugares praticados, associadas à importância das turbulências e do caráter acidentado do tempo, que as revolvem, misturam e separam. A etnografia que emerge daí é uma dimensão microssociológica que requer cuidado às dinâmicas dos fragmentos conexos ao todo, uma aderência às figurações e fulgurações paisageiras na cidade. Aqui, a experiência conjunta de ambas e o seu compromisso para com o avanço dos debates no campo antropológico, especialmente ao que se refere à Antropologia Urbana, têm relação direta com o cruzamento de linhagens presentes na abordagem sobre a cidade, e que dizem respeito às orientações que tiveram ao longos de seus estudos de mestrado: no caso da primeira por Ruben Oliven, e no da segunda, por Gilberto Velho. A menção a tais pensadores que se debruçaram sobre o «fenômeno urbano » e seus « desafios » reverbera, assim, na formação das idealizadoras do NAVISUAL-BIEV, e consequentemente nas suas formas de pensar as dimensões citadinas do viver social na cidade, o que constitui aspecto relevante, principalmente quando se pensa na gênese dos estudos sobre a cidade conduzidos pela antropologia no país, e os desdobramentos que resultaram em suas pesquisas de doutorado, por exemplo, que seguem como referenciais à antropologia que praticam no atual.

2. As camadas de gerações de antropólogos formados pelo Navisual-Biev ao longo dos quase 30 anos de sua existência. Estes dois projetos em consonância, no meu ponto de vista, estão longe de se constituírem como projetos de pesquisa de cunho pessoal, justo porque fazem parte de uma proposta didático-pedagógica de formação de antropólogos, que envolve aprendizagens em torno do métier antropológico, e que permite aos neófitos passarem a operar criativamente com um arcabouço teórico-metodológico que aciona saberes e fazeres em torno da produção de narrativas fotoetnográficas, da produção de coleções e na constatação de riquezas epistemológicas relativas às constelações de imagens capazes de serem descobertas, elaboradas, lapidadas pelo exercício criativo de uma etnografia engajada em princípios ético-estéticos, porque amparados numa forma muito própria de pensar a antropologia urbana, senão apenas para o sul do Brasil, para as cidades brasileiras.Há, portanto, camadas de memórias que cruzam linhagens e trajetórias pessoais inseridas no mundo acadêmico, que aproximam numa vibração feliz coletivos ao longo do tempo que dura a experiência do NAVISUAL-BIEV como um espaço cognitivo e sensível 
de criação conjunta, atravessado por congraçamentos, tensões e possibilidades nesses quase 30 anos de existência da parceria entre Cornelia e Ana Luiza.

Trajetória singular a do Núcleo de Antropologia Visual (NAVISUAL)/Banco de Imagens e Efeitos Visuais (BIEV) no panorama da Antropologia Brasileira Contemporânea, especialmente no que se refere à Antropologia Urbana produzida no país. Pelo menos é assim que o percebo quando manuseio o catálogo resultante da exposição fotográfica, que teve por curador o antropólogo Rafael Derois Santos com o apoio do Departamento de Difusão Cultural da Pró-Reitoria de Extensão da Universidade Federal do Rio Grande do Sul, que também coordenou a organização da publicação junto a equipe de pesquisadores, e compreendo o seu lugar como locus de produção de conhecimento antropológico sobre a cidade e de formação de profissionais interessados nos fenômenos urtbanos. Eu mesmo tenho minha formação ligada a ele e ao BIEV, ainda que de maneira errática, transitei por ambos os espaços em diferentes momentos da minha formação e carreira acadêmica.

A parceria do Navisual-Biev contribuiu para a formação de várias gerações de antropólogos que hoje atuam em diferentes partes do país e no exterior. A dinâmica dos coletivos em formação ao configurarem uma comunidade de interpretação e, portanto, narrativa, variou ao longo do tempo de acordo com a conformação de um cenário acadêmico que indica períodos, onde fulano ou sicrana, alunos da turma tal, moviam seus interesses em conexão aos projetos, ou mesmo, de pessoas que figuraram por longo período no cenário e que hoje circulam por outros, ou ainda, como dito antes a partir do meu caso, que erraticamente figuraram em momentos e produziram parcerias que orbitavam em torno do Navisual-Biev com suas coordenadoras e demais colegas.

Nestes termos, é preciso deixar claro que tais projetos são espaços de fluxo de pessoas, e engendram certo espírito de grupo que inevitavelmente constitui a formação acadêmica de quem por eles passam, pois aprende-se a lidar com as formas cooperativas e tensionais na produção do conhecimento, ou ainda, de que cognição e afeto participam de uma dramática que diz respeito ao próprio processo de pensar o pensamento, de produzir 
imagens e de aderir às feições imaginárias de uma paisagem que pulsam como memórias nos lugares. É isto que sempre levo comigo, e que opero a minha maneira na antropologia que pratico, assim como na formação dos estudantes na graduação/pós-graduação com os quais trabalho.

Então, participar destes projetos é aprender a jogar o social nas suas vicissitudes de integração/desintegração como devir de um coletivo que figura numa paisagem acadêmica que dura no tempo. Ou ainda, enquanto dimensão processual do conhecimento, tais experiências da imaginação criadora aplicadas à produção do conhecimento antropológico sobre a cidade revelam que eles próprios são experiências urbanas, cujas possibilidades conflitivas e afetuais de produzir congraçamentos pessoais e acadêmicos duram o tempo de permanência daquele ou daquelaque se engaja no devir de uma experiência coletiva, que segue pelo esforço de suas coordenadoras. Isto demonstra queao longo do tempo as sucessivas gerações que buscaram (e buscam) se iniciar no campo antropológico junto ao Navisual-Biev, sempre fluíram em torno das figuras que os coordenam, produzindo formas de associações, congraçamentos e tensões que renovam tanto o coletivo, quanto dispersam na paisagem intelectual antropológica figuras autônomas que produzem formas outras de interpretação sobre os fenômenos sociantropológicos, mais ou menos inspiradas na experiência com o coletivo sediado no Campus do Vale. Aí está, para mim, a sua potência didático-pedagógica, heurística e humana, que me fez voltar temporariamente a ele ${ }^{5}$.

3. As camadas de memórias de Porto Alegre emergem com força no percurso narrativo imagético-textual desenhado pelo experimento coletivo.O catálogo fornece muitas entradas ao leitor interessado na vida citadina portoalegrense. Ele permite uma incursão às feições plurais e paisageiras presentes no contemporâneo de uma metrópole brasileira de expressão austral, considerando-se a duração de seus processos citadinos de acoplamentos espaçotemporais de ritmos (de expansão/retraimento; construção/degradação ; (re)configuração ; decaimento/gentrificação, entre outros) no devir dos fenômenos sociais no mundo urbano, no delinemaneto tensional de suas marcas contextuais nas paisagens que identificam lugares/bairros/distritos; nas pulsações memoriais de seus territórios de pertença e

5 No momento realizo pós-doutorado com bolsa do CNPq junto ao Navisual-Biev, na Universidade Federal do Rio Grande do Sul (UFRGS), e atuo como professor na Universidade Federal do Pará (UFPA). 
existenciais e, por isso mesmo, nas transformações de sua fisionomia, mediante a dinâmica dos congraçamentos e conflitos, das lembranças e esquecimentos, das motivações que edificam e/ou arruínam.

Fica claro ao leitor atento que percorre sensivelmente o universo que emerge do referido catálogo, que para alcançar as vibrações citadinas desde o campo antropológico é preciso tanto apoiar-se num referencial teórico-metodológico disciplinar que orienta o olhar interessado pela cidade - que é, pelo menos em parte, aquele que as cartas sugerem - para acessar os fenômenos sociais que abarca; quanto aderir às imagens suscitadas pelas vibrações dessa cidade praticada, a fim de estabelecer percursos e itinerâncias possíveis ao deambularpelos lugares de maneira atenta a uma antropologa social do sensível, que é justo uma maneira de acessar certas dimensões do imaginário que pulsam numa metrópole como Porto Alegre.

É devido a isso que é preciso considerara movência urbana (em todos os sentidos e « vetores de relação») por intermédio das deambulações interessadas, das flanéries como metáforas de uma aventura urbana cuja poética tem relação com a errância e o deixar-se levar pela força sensível das imagens, ao jogo social simmeliano e, portanto, positivo entre proximidade e distância, enfim, de lidar com as fronteiras e de experimentar-se estrangeiro na sua própria cidade, apesar de aparentemente conhecê-la. Neste sentido, entendo que a proposta do experimento é o de fluir nas paisagens como dimensão do seu devir: o antropólogo segue sendo o narrador das paisagensquando adentra as paisagens do outro, que paradoxalmente, são as suas já que também é habitante da cidade e figura nela como paisagem. Talvez esta seja uma forma de ler o catálogo muito pessoal porque é como o vejo ressoar no meu próprio trabalho. Além disso, quando se observa o catálogo fica claro que o antropólogo adere à força criativa de artistas de rua a partir de seus grafites e lambes, aos lugares com rastros de trajetorias e memorias que são captadas e, posteriormente, apresentadas na logica de uma coleção etnográfica, orientada por um campo semantico que segue o tesaurus conceitual do Banco de Imagens (BIEV). 
A cidade, neste caso, é uma dimensão praticada das espacialidades dos lugares que as derivas urbanas propiciam, e terão consigo sempre um caráter tensional porque detentoras de rítmicas ora turbulentas ora apaziguadas de suas forças na proliferação de formas (envolvendo encaixes-desencaixes temporais, (re)configurações e desfigurações dos arranjos entre lugares e espaços, (des)continuidades de projetos que (re)definem o seu corpo diante de escolhas que indicam perdurâncias e fugacidades de conteúdos, gostos e estilos ao sabor das épocas) que se assentam e se conformam no e ao cotidiano dos grupos sociais, pela elaboração criativa de paisagens por pessoas, coletivos mais ou menos efêmeros, por comunidades de destino que praticam os lugares citadinos e configuram paisagens existenciais entranhadas nas memórias dos bairros. É disso que o catálogo nos fala: dessas paisagens polissêmicas portoalegrenses e de suas poéticas.

As sobreposições e atravessamentos de camadas que conformam o mundo urbano encontram o olhar atento daquele que se debruça sobre o corpo dinâmico da urbe. Portanto, na tessitura imagético-textual do catálogo-experimento coletivo há diversas formas de acessar o sensível da vida social numa cidade pela polissemia das imagens, das suas paisagens inscritas, descritas e transcriadas nas fotografias e textos. Existem diversas maneiras de acessarmos o rico conteúdo que o catálogo apresenta ao leitor interessado pelo « fenômeno urbano » que se desdobra ao longo do tempo numa cidade como Porto Alegre, e que é justo o convite a percorrê-lo: cada um deve descobrir a sua forma de exercitar o percurso. A paisagem textual intersubjetiva elaborada criativamente pelo coletivo de pesquisadores é uma bricolagem/montagem imagético-epistolar sensível, um experimento poético-narrativo de jovens estudantes que vivenciaram trabalhos de campo nas ruas da metrópole com câmeras nas mãosmediante o exercício de uma etnografia de rua, que eu mesmo experimento desde longa data ${ }^{6}$.

Trata-se de mais uma produção sensível de um coletivo que dura e se transforma ao longo do tempo, movido pelo diálogo com os estudos de memória e do imaginário, o que deriva daí uma preocupação teórico-metodológica com a produção de narrativas visuais (lançando mão de técnicas/ferramentas voltadas a uma antropologia visual), como uma

6 Basta ver os trabalhos de vários antropólogos formados por Cornelia e Ana, que aparecem no livro organizado por ambas intitulado Etnografia de Rua, onde publiquei um estudo sobre uma padaria na Cidade Baixa, bairro de Porto Alegre. 
preocupação com a formação de constelações de imagens e suas convergências (e aí, com uma antropologia da imagem). Belo esforço de durar de um grupo cujas reverberações memoriais vibram em mim e naqueles que convive(ra)m com Cornelia e Ana Luiza, na sua incessante dedicação às invenções culturais cotidianas que fazem de Porto Alegre o que ela é ao longo do tempo.

No final do catálogo existem quatro breves relatos das saídas de campo, são singelas narrativas de encontros com pessoas e lugares na cidade de Porto Alegre que falam dessa dimensão micro da vida social, tão rica e plural, que pulsa numa cidade brasileira.

Recebido 09 de setembro 2018 Aprovado 15 de dezembro 2018 